\title{
Abkürzungen in Titelwiedergaben
}

Abb.

Abbildung(en)

Abdr.

Abdruck

Abt.

Abteilung

a.G.

als Gast

Akad.

Akademie

Anh.

Anhang

Anm.

Anmerkung(en)

Anth.

Anthologie

Auff.

Aufführung(en)

Aufl.

Auflage

Ausw./ausgew.

Auswahl/ausgewählt

Ausz./auszugsw. Auszug/auszugsweise

Autorenkoll.

Autorenkollektiv

autoris.

autorisiert

Bd./Bde.

Band/Bände

Bearb./bearb.

Bearbeiter, Bearbeitung/bearbeitet

beigef.

beigefügt

Beih.

Beiheft(e)

Beil.

Beilage(n)

Beitr.

Beitrag, Beiträge

Bem.

Bemerkung(en)

Bibl.

Bibliothek

bibl.

biblisch

Bibliogr.

Bibliographie

Biogr./biogr

Biographie/biographisch

B1.

Blatt, Blätter

dargest.

dargestellt

Diss.

Dissertation

Dok.

Dokument(e)

Dr.

Druck

EA

Erstaufführung

Ed.

Edition

eigentl.

eigentlich

Einf./eingef.

Einführung/eingeführt

Einl./eingel.

Einleitung/eingeleitet

Endred.

Endredaktion

enth.

enthält

Erg.

Ergänzung(en) 
erkl.

erklärt

Erl./erl.

Erläuterung(en)/erläutert

erw.

erweitert

Erz.

Erzählung

EST

Einheitssachtitel

Ex.

Exemplar(e)

farb.

farbig

Fass.

Fassung

fortgef.

fortgeführt

Ged.

Gedicht

gedr.

gedruckt

gef.

gefaltet

gek.

gekürzt

ges.

gesammelt

gez.

gezählt

gez.

gezeichnet

GT

Gesamttitel

$\mathrm{H}$.

Heft(e)

Habil.-Schr.

Habilitationsschrift

Hinw.

Hinweis(e)

hist.

historisch

Hrsg./hrsg.

Herausgeber/herausgegeben

Ill./ill.

Illustration(en)/illustriert

Inst.

Institut

Jg.

Jahrgang

Jh.

Jahrhundert

Kap.

Kapitel

Kom.

Komödie

Komm./komm.

Kommentar/kommentiert

Kt.

Karte(n)

$\mathrm{L}$

Literatur- und Rezensionsnachweis(e)

Ltg.

Leitung

Lit./lit.

Literatur/literarisch

Literaturang.

Literaturangaben

Literaturverz.

Literaturverzeichnis

Lustsp.

Lustspiel

Mitarb.

Mitarbeit

Mitt.

Mitteilung(en)

Mitw.

Mitwirkung

Ms.

Manuskript

NA

Neuausgabe 


\begin{tabular}{|c|c|}
\hline Nachtr. & Nachtrag \\
\hline Nachw. & Nachwort \\
\hline N.F. & Neue Folge \\
\hline NT & Nebentitel \\
\hline Nov. & Novelle \\
\hline num. & numeriert \\
\hline Nr. & Nummer \\
\hline Orig. & Original/original \\
\hline Personenreg. & Personenregister \\
\hline Portr. & Porträt \\
\hline Pseud. & Pseudonym \\
\hline PST & Parallelsachtitel \\
\hline PT & Paralleltitel \\
\hline Rad. & Radierung(en) \\
\hline Red. & Redakteur/Redaktion(en) \\
\hline Reg. & Register \\
\hline Repr. & Reprint \\
\hline Reprod. & Reproduktion(en) \\
\hline Rev./rev. & Revolution/revolutionär \\
\hline rev. & revidiert \\
\hline S. & Seite(n) \\
\hline Sacherkl. & Sacherklärung(en) \\
\hline Schausp. & Schauspiel \\
\hline sign. & signiert \\
\hline Sp. & Spalte(n) \\
\hline SR & Sammelrezension \\
\hline $\mathrm{T}$. & Teil(e) \\
\hline Taf. & Tafel(n) \\
\hline Trag. & Tragödie \\
\hline Trauersp. & Trauerspiel \\
\hline Tsd. & Tausend \\
\hline UA & Uraufführung \\
\hline überarb. & überarbeitet \\
\hline Übers./übers. & Übersetzung, Übersetzer/übersetzt \\
\hline Übertr./übertr. & Übertragung/übertragen \\
\hline u.d.T. & unter dem Titel \\
\hline Univ. & Universität \\
\hline unverkäufl. & unverkäuflich \\
\hline veränd. & verändert \\
\hline verb. & verbessert \\
\hline Verf. & Verfasser \\
\hline
\end{tabular}




$\begin{array}{ll}\text { Verl. } & \text { Verlag } \\ \text { verm. } & \text { vermehrt } \\ \text { Veröff./veröff. } & \text { Veröffentlichung/veröffentlicht } \\ \text { vers. } & \text { versehen } \\ \text { Verz. } & \text { Verzeichnis } \\ \text { Vorsp. } & \text { Vorspiel } \\ \text { Vorw. } & \text { Vorwort } \\ \text { wirkl. } & \text { wirklich } \\ \text { Wiss./wiss. } & \text { Wissenschaft(en)/wissenschaftlich } \\ \text { Worterkl. } & \text { Worterklärung(en) } \\ \text { zahlr. } & \text { zahlreich(e) } \\ \text { Zeichn. } & \text { Zeichnung(en) } \\ \text { zeitgen. } & \text { zeitgenössisch } \\ \text { Zentralinst. } & \text { Zentralinstitut } \\ \text { Zs. } & \text { Zeitschrift } \\ \text { Zsarb. } & \text { Zusammenarbeit } \\ \text { Zsfassung } & \text { Zusammenfassung } \\ \text { zsgest. } & \text { zusammengestellt } \\ \text { Zsstellung } & \text { Zusammenstellung } \\ \text { z.T. } & \text { zum Teil } \\ \text { Ztg. } & \text { Zeitung } \\ \text { zugl. } & \text { zugleich } \\ \text { zweisprach. } & \text { zweisprachig } \\ & \end{array}$


